EPJ Web of Conferences 29, 00031 (2012)

DOI: $10.1051 /$ epjconf/20122900031

(C) Owned by the authors, published by EDP Sciences, 2012

\title{
Crystal structure, NMR study, dc-conductivity and dielectric relaxation studies of a new compound $\left[\mathrm{C}_{2} \mathrm{H}_{10} \mathrm{~N}_{2}\right] \mathrm{Cd}(\mathrm{SCN})_{2} \mathrm{Cl}_{2}$
}

\author{
K. Saidi ${ }^{\mathrm{a}, 1}$, S. Kamoun ${ }^{\text {a }}$, H. F. Ayedi ${ }^{\mathrm{a}}$ and M. Gargouri ${ }^{\mathrm{b}}$ \\ ${ }^{1}$ Laboratoire de Génie des Matériaux et Environnement, ENIS, 1173, Université de Sfax, Tunisia \\ ${ }^{2}$ Laboratoire de l'état solide, Faculté des sciences de Sfax, B.P.1171, 3000 Sfax, Tunisia
}

\begin{abstract}
The crystal structure, the solid NMR spectroscopy and the complex impedance study have been carried out on $\left[\mathrm{C}_{2} \mathrm{H}_{10} \mathrm{~N}_{2}\right] \mathrm{CdCl}_{2}(\mathrm{SCN})_{2}$. Characterization by single crystal $\mathrm{X}$-ray crystallography shows that the cadmium atoms have à $2 \mathrm{~N} 2 \mathrm{~S} 2 \mathrm{Cl}$ hexa-coordination sphere, exhibiting pseudo-octahedral geometry. The cadmium atoms are bridged by two thiocyanate ions generating 1-D polymeric-chains. These chains are themselves interconnected by means of $\mathrm{N}-\mathrm{H}$...Cl(NCS) hydrogen bonds originating from the organic cation $\left[\left(\mathrm{NH}_{3}\right)_{2}\left(\mathrm{CH}_{2}\right)_{2}\right]^{2+}$. ${ }^{111} \mathrm{Cd}$ isotropic chemical shifts span a range of 268ppm. The cadmium atom exhibits multiplets that result from ${ }^{111} \mathrm{Cd}-{ }^{14} \mathrm{~N}$ spin-spin coupling. Examination of ${ }^{111} \mathrm{Cd}$ and ${ }^{13} \mathrm{C}$ MAS line shapes shows direct measurement of the indirect spin-spin coupling constant ${ }^{2} \mathrm{~J}\left({ }^{111} \mathrm{Cd},{ }^{14} \mathrm{~N}\right)=105 \mathrm{~Hz}$ and the dipolar coupling constant of $1381 \mathrm{~Hz}$. Impedance spectroscopy measurements of $\left[\mathrm{C}_{2} \mathrm{H}_{10} \mathrm{~N}_{2}\right] \mathrm{CdCl}_{2}(\mathrm{SCN})_{2}$ have been studied from $209 \mathrm{~Hz}$ to $5 \mathrm{MHz}$ over the temperature range $300-370 \mathrm{~K}$. The Cole-Cole (Z' versus Z') plots are fitted to two equivalent circuits models. The formalism of complex permittivity and impedance were employed to analyze the experimental data. The dc conductivity follows the Arrhenius relation with an activation energy $E_{a}=0.54(3) \mathrm{eV}$.
\end{abstract}

\section{Introduction}

Organometallic complexes based on cadmium-thiocyanates have attracted a great research attention because they exhibit excellent physical properties such as nonlinear optical (NLO) behavior. These materials coupling the ambidentate nature and bridging capacity of thiocyanates with the thermal stability, structural diversity and simplicity in processing of organic molecules can enlarge their field of applications [1]. Thiocyanate and isothiocyanate anions can coordinate through either the nitrogen or the sulfur atom or both to the metal center. $\mathrm{Cd}(\mathrm{II})$ has the particularity to exhibit both (S and $\mathrm{N}$ ) bonding modes to (SCN) $)^{-}$ligands tending to form a 6- coordinated octahedral complexes.

In this paper we report the synthesis, the crystal structure, the heteronuclear ${ }^{111} \mathrm{Cd},{ }^{13} \mathrm{C} \mathrm{CP} / \mathrm{MAS}$ NMR spectroscopy and impedance spectroscopy of a novel 1-D coordination array $\left[\mathrm{C}_{2} \mathrm{H}_{10} \mathrm{~N}_{2}\right] \mathrm{CdCl}_{2}(\mathrm{SCN})_{2}$. The impedance spectroscopic measurements were performed in a wide temperature range from 300 to $370 \mathrm{~K}$. the electrical relaxation analysis was performed using the

1 e-mail : khaoulaslaheddine@yahoo.fr

This is an Open Access article distributed under the terms of the Creative Commons Attribution License 2.0, which permits unrestricted use, distribution, and reproduction in any medium, provided the original work is properly cited. 
conductivity $\sigma^{*}(\omega)=\sigma^{\prime}(\omega)+\mathrm{i} \sigma^{\prime \prime}(\omega)$ and dielectric $\varepsilon^{*}(\omega)=\varepsilon^{\prime}(\omega)+\mathrm{i} \varepsilon^{\prime \prime}(\omega)$ formalism. The temperature and frequency dependence of the dielectric properties of the compound is reported.

\section{Experimental}

Crystals of ethylenediammonium bis chloro diisothiocyanato cadmium (II) were prepared by dissolving in aqueous medium a stoichiometric mixture of $\mathrm{Cd}(\mathrm{SCN})_{2}$ and ethylenediammonium dichloride according to the following chemical reaction.

$$
\mathrm{C}_{2} \mathrm{H}_{10} \mathrm{~N}_{2} \mathrm{Cl}_{2}+\mathrm{Cd}(\mathrm{SCN})_{2} \quad\left[\mathrm{C}_{2} \mathrm{H}_{10} \mathrm{~N}_{2}\right] \mathrm{CdCl}_{2}(\mathrm{SCN})_{2}
$$

The experimental conditions used for the single crystal data collection are reported in Table1. All calculations were performed using SHELXL-97 [2] computer programs included in the WINGX software package [3]. The structural figures were carried on with Mercury 2.3 supplied by crystal impact [4]. The atomic scattering factors were taken from the International Tables for X-ray Crystallography [5]. The structure was solved by the heavy-atom method. The position of nitrogen, sulfur and chlorine atoms were deduced from their three-dimensional Patterson maps using the SHELXS-97 program, while the remaining other atoms were located by means of successively Fourier maps. Full matrix refinement with anisotropic thermal parameters for all non-hydrogen atoms and isotropic thermal parameters for $\mathrm{H}$ atoms converged to a final $\mathrm{R}$ value of 0.0249 .

${ }^{13} \mathrm{C}$ and ${ }^{111} \mathrm{Cd}$ solid-state NMR spectra were recorded on a BRUKER $300 \mathrm{MHz}$ (7.1T) spectrometer using cross polarization (CP) and magic- angle spinning(MAS) with $63.633 \mathrm{MHz}$ Larmor frequency for ${ }^{111} \mathrm{Cd}$ and $75.467 \mathrm{MHz}$ for ${ }^{13} \mathrm{C}$. Impedance spectroscopy measurements have been carried out from $209 \mathrm{~Hz}$ to $5 \mathrm{MHz}$ over the temperature range $300-370 \mathrm{~K}$ using a TEGAM 3550 ALF automatic bridge monitored by a micro-computer. Crystallographic data for the structure reported in the paper (excluding structure factors) have been deposited with the Cambridge Crystallographic Data Centre, CCDC, no 818072 in the European Physical Journal.

\section{Results and discussion}

\subsection{Structure description}

Figure1 shows the ORTEP drawing of the molecular structure of $\left[\mathrm{C}_{2} \mathrm{H}_{10} \mathrm{~N}_{2}\right] \mathrm{CdCl}_{2}(\mathrm{SCN})_{2}$ with the atom numbering scheme, while Figure2 and Figure3 shows the 1D network character of the complex. Selected bond distances and bond angles are listed in table2. The structure consists of doubly SCN-bridged 1-dimensional chains along the crystallographic (100) direction (Figure2). Each cadmium atom is pseudo-octahedrally coordinated by two trans-coordinated chloride anions, two trans-arranged sulfur atoms and two trans-arranged nitrogen atoms from the bridging thiocyanate groups. The double bridging action of $\mathrm{SCN}^{-}$gives rise to eight-membered $\mathrm{Cd}_{2}(\mathrm{SCN})_{2}$ rings in the chair conformation because of the almost linear SCN group ( $\mathrm{S}-\mathrm{C}-\mathrm{N}=179.0(3))$. The centeroid of the rings is a center of inversion. These chains build up the 1D chain through their corner-sharing action at two cadmium atoms. Weak intrachain $\mathrm{N}-\mathrm{H}$... NCS and $\mathrm{N}-\mathrm{H} \ldots \mathrm{Cl}$ hydrogen bonds are 
formed from each ethylenediammonium groups to the nitrogen and chlorine donor atoms of the $\left[\mathrm{CdCl}_{2}(\mathrm{SCN})_{2}\right]_{n}^{2-}$ anionic chains.

Table 1. Crystal data and structure refinement for $\left[\mathrm{C}_{2} \mathrm{H}_{10} \mathrm{~N}_{2}\right] \mathrm{Cd} \mathrm{Cl}_{2}(\mathrm{SCN})_{2}$

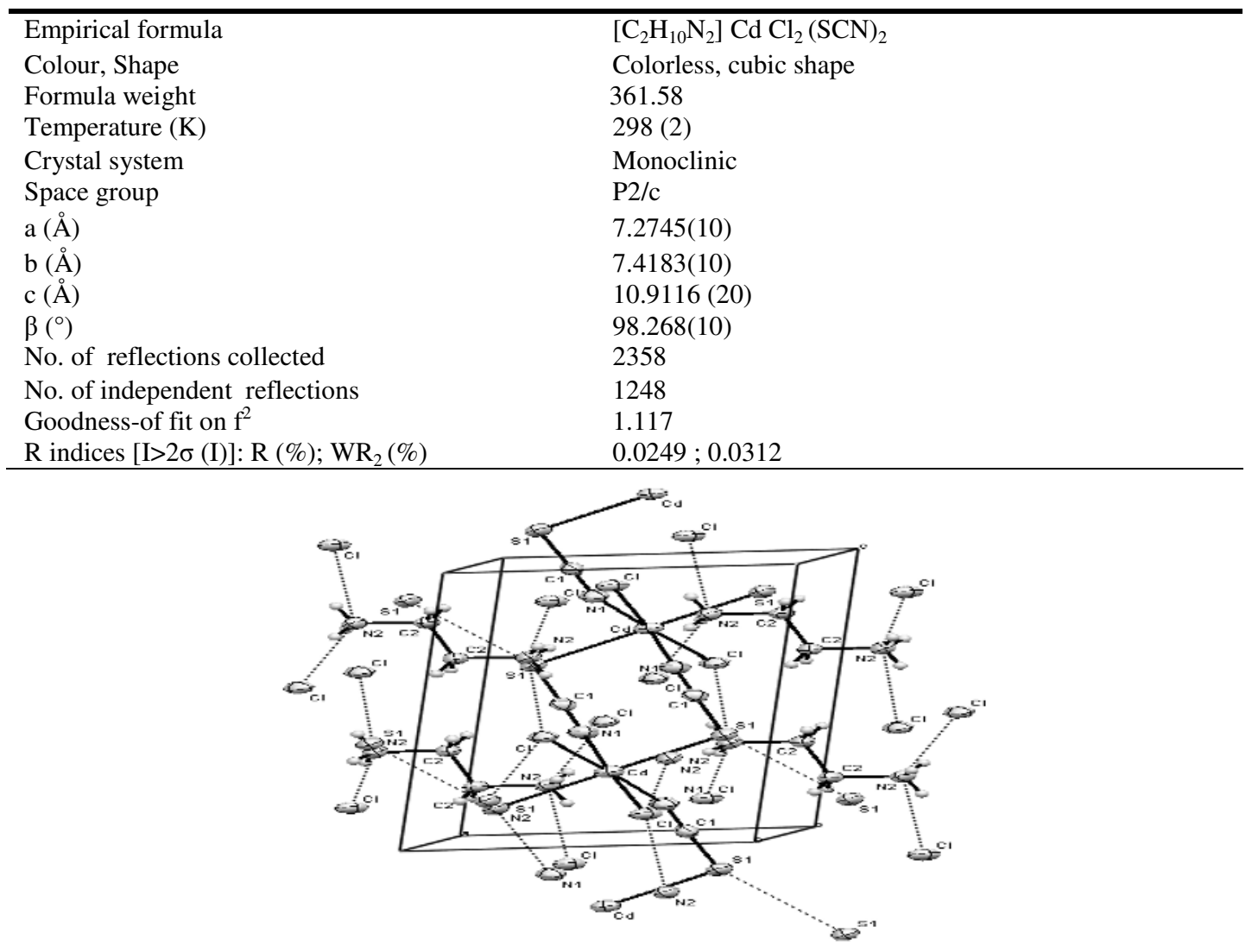

Fig.1. ORTEP stereoscopic projection of the crystal packing.

Table 2. Principal intermolecular distances $(\AA)$ and bond angles $\left({ }^{\circ}\right)$

\begin{tabular}{llll}
\hline Atome & Distances & Atome & Angles \\
$\mathrm{Cd}-\mathrm{S}(1):$ & $2.7689(4)$ & $\mathrm{N}(1)-\mathrm{Cd}-\mathrm{S}(1):$ & $89.75(0)$ \\
$\mathrm{Cd}-\mathrm{S}(1)^{(\mathrm{j})}:$ & $2.7689(4)$ & $\mathrm{Cl}-\mathrm{Cd}-\mathrm{S}(1):$ & $93.13(0)$ \\
$\mathrm{Cd}-\mathrm{Cl}:$ & $2.5653(3)$ & $\mathrm{Cl}^{(\mathrm{j})}-\mathrm{Cd}-\mathrm{S}(1):$ & $89.08(3)$ \\
$\mathrm{Cd}-\mathrm{Cl}{ }^{(\mathrm{j})}:$ & $2.5653(3)$ & $\mathrm{S}(1)^{(\mathrm{j})}-\mathrm{Cd}-\mathrm{S}(1):$ & $176.87(4)$ \\
$\mathrm{Cd}-\mathrm{N}(1):$ & $2.3710(3)$ & $\mathrm{Cl}^{(\mathrm{j})}-\mathrm{Cd}-\mathrm{N}(1):$ & $92.00(9)$ \\
$\mathrm{Cd}-\mathrm{N}(1)^{(\mathrm{j})}:$ & $2.3710(3)$ & $\mathrm{S}(1)^{(\mathrm{j})}-\mathrm{Cd}-\mathrm{N}(1):$ & $87.96(6)$ \\
$\mathrm{N}(1)-\mathrm{C}(1):$ & $1.1647(35)$ & $\left.\mathrm{N}^{(1)}\right)^{(\mathrm{j})}-\mathrm{Cd}-\mathrm{N}(1):$ & $85.68(13)$ \\
$\mathrm{N}(2)-\mathrm{C}(2):$ & $1,157(7)$ & $\mathrm{Cl}^{(\mathrm{j})}-\mathrm{Cd}-\mathrm{Cl}:$ & $90.46(4)$ \\
$\mathrm{S}(1)-\mathrm{C}(1)^{(\mathrm{i})}:$ & $1.6533(3)$ & $\mathrm{S}(1)^{(\mathrm{j})}-\mathrm{Cd}-\mathrm{Cl}:$ & $89.08(3)$ \\
$\mathrm{S}(1)^{(\mathrm{i})}-\mathrm{C}(1):$ & $1.6533(3)$ & $\mathrm{N}(1)^{(\mathrm{j})}-\mathrm{Cd}-\mathrm{S}(1):$ & $87.96(6)$ \\
$\mathrm{N}(1)^{(\mathrm{j})}-\mathrm{Cd}-\mathrm{C} 1^{(\mathrm{j})}:$ & $176.24(7)$ & $\mathrm{N}(1)^{(\mathrm{j})}-\mathrm{Cd}-\mathrm{C} 1:$ & $92.00(7)$ \\
$\mathrm{N}(1)^{(\mathrm{j})}-\mathrm{Cd}-\mathrm{S}(1)^{(\mathrm{j})}:$ & $89.75(6)$ & $\mathrm{S}(1)^{(\mathrm{j})}-\mathrm{Cd}-\mathrm{C} 1^{(\mathrm{j})}:$ & $93.13(3)$ \\
$\mathrm{C}(1)-\mathrm{S}(1)^{(\mathrm{j})}-\mathrm{N}(1):$ & $179.0(3)$ & & \\
\hline $\mathrm{Codes}:(\mathrm{i}) \mathrm{x},-\mathrm{y}-1, \mathrm{Z}+1 / 2 ;(\mathrm{j})-\mathrm{x}+1, \mathrm{y}-\mathrm{Z}+1 / 2$ &
\end{tabular}

Symmetry Codes: (i) $\mathrm{x},-\mathrm{y}-1, \mathrm{z}+1 / 2 ;(\mathrm{j})-\mathrm{x}+1, \mathrm{y},-\mathrm{z}+1 / 2$ 


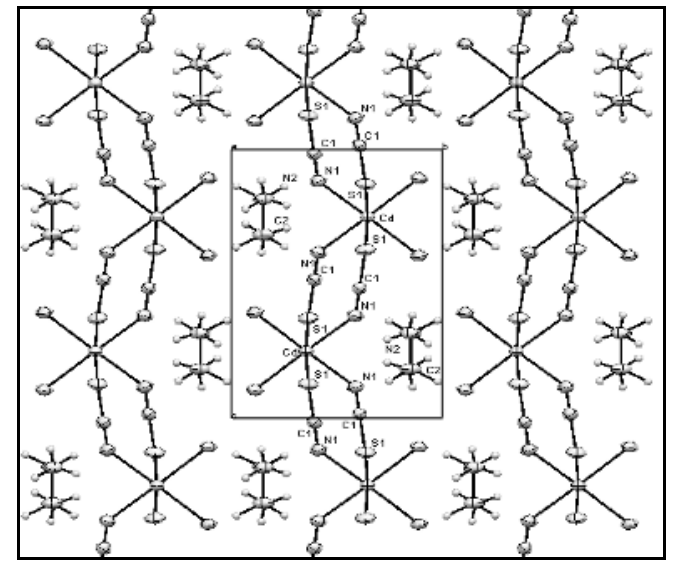

Fig.2. Projection along the a-axis of $\mathrm{C}_{2} \mathrm{H}_{10} \mathrm{~N}_{2} \mathrm{CdCl}_{2}$ $(\mathrm{SCN})_{2}$

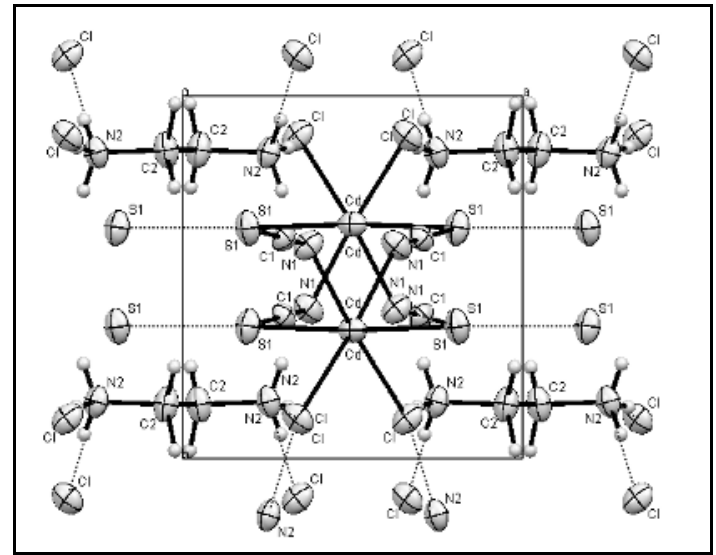

Fig.3. Projection along the c-axis of $\mathrm{C}_{2} \mathrm{H}_{10} \mathrm{~N}_{2} \mathrm{CdCl}_{2}$ $(\mathrm{SCN})_{2}$.

\subsection{NMR Spectroscopy}

The isotropic band of ${ }^{111} \mathrm{Cd}$ and ${ }^{13} \mathrm{C}, \mathrm{CP}-\mathrm{MAS}-\mathrm{NMR}$ spectrum of the title compound rotating at magic angle with frequency $8000 \mathrm{~Hz}$ are given in Figure 4 and Figure 5.

The ${ }^{111} \mathrm{Cd}$ CP/MAS NMR spectrum consists of five peaks of relative intensities 1:2:3:2:1 that indicate a coupling of ${ }^{111} \mathrm{Cd}$ with two ${ }^{14} \mathrm{~N}$ nuclei [6]. The best agreement between the experimental and the calculated spectrum was achieved by introducing two equivalent ${ }^{14} \mathrm{~N}$ nuclei with the same values of $\mathrm{J}=105 \mathrm{~Hz}$ and $\mathrm{d}=-3$. This is consistent with the structure determination by X-ray crystallography which indicates that the cadmium is surrounded octahedrally by two equivalent nitrogen, two sulfur atoms, and two chlorine atoms.

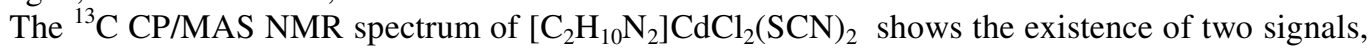
with the values of the isotropic chemical shifts $44.89 \mathrm{ppm}$ and $129.16 \mathrm{ppm}$. These signals correspond respectively to the carbon atoms of the ethylenediammonium cation and the thiocyanate anion.

According to the literature on the solid state, the coupling between ${ }^{13} \mathrm{C}$ and ${ }^{14} \mathrm{~N}$ is essentially due to the quadrupole interaction on the ${ }^{14} \mathrm{~N}$ nucleus, and it appears as an asymmetric doublet (with intensity 2:1) [7].

The splitting between the peaks due to the ${ }^{14} \mathrm{~N} \mathrm{~m}=0$ and $\mathrm{m}= \pm 1$ spin states correspond to $-3 \mathrm{~d}$, where $\mathrm{d}$ is the residual dipolar coupling [8] given by:

$$
d=-\frac{3 \chi^{D}}{20 Z}\left(3 \cos ^{2} \beta^{D}-1+\eta \sin ^{2} \beta^{D} \cos 2 \alpha^{D}\right)
$$

with the quadrupolar coupling constant, $\chi=\mathrm{e}^{2} \mathrm{Qq}_{\mathrm{zz}} / \mathrm{h}$, the asymmetry parameter of the EFG tensor, $\eta=\left(q_{x x}-q_{y y}\right) / q_{z z}$, and the Larmor frequency, $Z=\gamma_{S} B_{0} / 2 \pi$, of the spin-S nucleus. The dipolar coupling constant $\mathrm{D}$ is given by:

$$
D=\left(\frac{\mu_{0}}{4 \pi}\right) \frac{\gamma_{I} \gamma_{S}}{r_{I S}^{3}}\left(\frac{h}{2 \pi}\right)
$$

and the azimuthal and polar angles, $\alpha^{\mathrm{D}}$ and $\beta^{\mathrm{D}}$ define the orientation of the dipolar vector, $\mathrm{r}_{\mathrm{IS}}$ with respect to the principal axis system of the EFG tensor. 


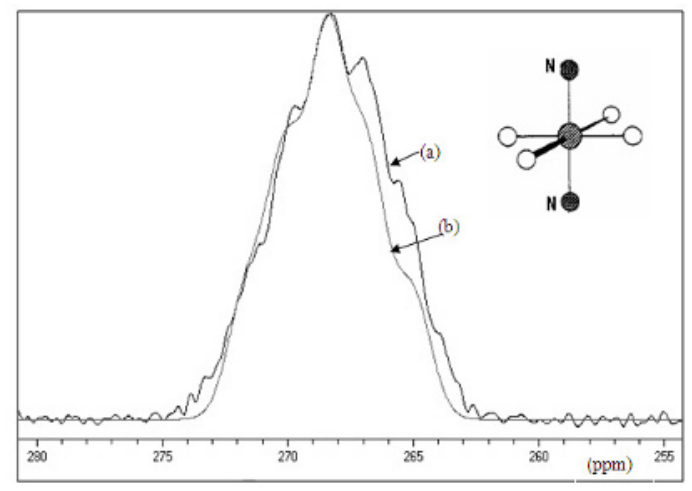

Fig.4. Isotropic region of the ${ }^{111} \mathrm{Cd}$ MAS NMR spectrum of $\mathrm{C}_{2} \mathrm{H}_{10} \mathrm{~N}_{2} \mathrm{Cd}(\mathrm{SCN})_{2}(\mathrm{Cl})_{2}$ having spin-spin coupling of ${ }^{111} \mathrm{Cd}$ to two ${ }^{14} \mathrm{~N}$ nuclei: (a) experimental spectrum; (b): calculated spectrum.

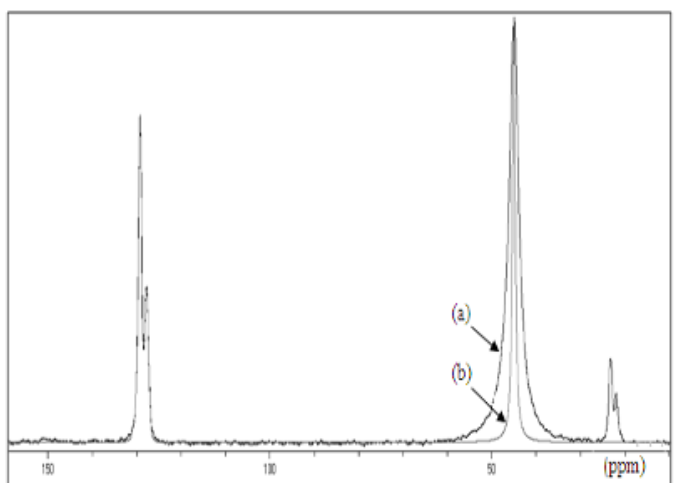

Fig.5. ${ }^{13} \mathrm{C}$ CP/MAS spectrum of $\mathrm{C}_{2} \mathrm{H}_{10} \mathrm{~N}_{2}$ $\mathrm{Cd}(\mathrm{SCN})_{2}(\mathrm{Cl})_{2}$ having direct dipolar coupling to ${ }^{14} \mathrm{~N}$ nuclei: (a) experimental spectrum; (b): calculated spectrum.

In our case, a splitting of $104 \mathrm{~Hz}$ is observed, which corresponds to a value of $\mathrm{d}=-34.6 \mathrm{~Hz}$. These values are in agreement with those reported by Klauss Eichele et al. and Olivieri et al [8].

The spectrum was simulated using the ${ }^{14} \mathrm{~N},{ }^{13} \mathrm{C}$ dipolar coupling constant for one site, $\mathrm{D}=1381 \mathrm{~Hz}$ which correspond to $\mathrm{r}_{\mathrm{CN}}=1.165(4) \AA$ and varying the quadrupole coupling constant $\chi$ (see figure 5).

\subsection{Impedance analysis and equivalent circuit}

Figure 6 shows typical complex impedance for $\left[\mathrm{C}_{2} \mathrm{H}_{10} \mathrm{~N}_{2}\right] \mathrm{CdCl}_{2}(\mathrm{SCN})_{2}$ at some selected temperatures. In all the cases the experimental complex impedance plots a depressed semicircle was observed. Above $330 \mathrm{~K}$ the depressed semicircles are accompanied by a straight line on the low frequency side, suggesting electrolyte-electrode polarization at the blocking electrode [9]. Such depression of the semicircle may originate from the presence of distribution in relaxation time within the bulk response. The radius of the semicircle decreases with increasing temperature due to the increase in the conductivity of the sample. At higher temperature the electrode effect becomes predominant, with a spike at lower frequencies. Our experimental results suggest that the depressed semicircles in the impedance spectra correspond to the bulk behavior of the sample, as will be explained below, and there is no grain boundary contribution to the impedance spectra. Two equivalent circuits appropriate to these plots are shown in the inset of figure 5 according to the temperatures range. Below $330 \mathrm{~K}$ we have performed a simulation of an equivalent circuit consisting only of two Rp1// CPE1 and Rp2// CPE2 elements connected in series as shown in the inset of figure 6 which corresponding to the bulk and electrode effects, respectively. Above $330 \mathrm{~K}$ a constant phase element CPE3 acting as a blocking double layer capacitance is added in series to the former equivalent circuit

The real and imaginary components of the whole impedance of this circuit were calculated according to the following expressions:

- $\mathrm{T}<330 \mathrm{~K}$

$$
Z^{\prime}=\frac{R_{p 1}^{2} Q_{1} \omega^{\alpha 1} \cos \left(\frac{\alpha_{1} \pi}{2}\right)+R_{p 1}}{\left(1+R_{p 1} Q_{1} \omega^{\alpha 1} \cos \left(\alpha_{1} \frac{\pi}{2}\right)\right)^{2}+\left(R_{p 1} Q_{1} \omega^{\alpha 1} \sin \left(\alpha_{1} \frac{\pi}{2}\right)^{2}\right.}+\frac{R_{p 2}^{2} Q_{2} \omega^{\alpha 2} \cos \left(\frac{\alpha_{2} \pi}{2}\right)+R_{p 2}}{\left(1+R_{p 2} Q_{2} \omega^{\alpha 2} \cos \left(\alpha_{2} \frac{\pi}{2}\right)\right)^{2}+\left(R_{p 2} Q_{2} \omega^{\alpha 2} \sin \left(\alpha_{2} \frac{\pi}{2}\right)\right)^{2}}
$$


$Z^{\prime \prime}=\frac{R_{p 1}^{2} Q_{1} \omega^{\alpha 1} \sin \left(\frac{\alpha_{1} \pi}{2}\right)}{\left(1+R_{p 1} Q_{1} \omega^{\alpha 1} \cos \left(\alpha_{1} \frac{\pi}{2}\right)\right)^{2}+\left(R_{p 1} Q_{1} \omega^{\alpha 1} \sin \left(\alpha_{1} \frac{\pi}{2}\right)\right)^{2}}+\frac{R_{p 2}^{2} Q_{2} \omega^{\alpha 2} \sin \left(\frac{\alpha_{2} \pi}{2}\right)}{\left(1+R_{p 2} Q_{2} \omega^{\alpha 2} \cos \left(\alpha_{2} \frac{\pi}{2}\right)\right)^{2}+\left(R_{p 2} Q_{2} \omega^{\alpha 2} \sin \left(\alpha_{2} \frac{\pi}{2}\right)\right)^{2}}$

where $\mathrm{Rp}$ is the bulk resistance and the impedance of CPE is $z_{C P E}=1 / Q(i \omega)^{\alpha}$, where $\mathrm{Q}$ indicates the value of capacitance of the CPE element and $\alpha$ is the fractal exponent.

- $\quad \mathrm{T}>330 \mathrm{~K}$

$$
\begin{gathered}
Z^{\prime \prime}=\frac{R_{p 1} Q_{1} \omega^{\alpha 1} \cos \left(\frac{\alpha_{1} \pi}{2}\right)+R_{p 1}}{\left(1+R_{p 1} Q_{1} \omega^{\alpha 1} \cos \left(\alpha_{1} \frac{\pi}{2}\right)\right)^{2}+\left(R_{p 1} Q_{1} \omega^{\alpha 1} \sin \left(\alpha_{1} \frac{\pi}{2}\right)\right)^{2}}+\frac{R_{p 2} Q_{2} \omega^{\alpha 2} \cos \left(\frac{\alpha_{2} \pi}{2}\right)+R_{p 2}}{\left(1+R_{p 2} Q_{2} \omega^{\alpha 2} \cos \left(\alpha_{2} \frac{\pi}{2}\right)\right)^{2}+\left(R_{p 2} Q_{2} \omega^{\alpha 2} \sin \left(\alpha_{2} \frac{\pi}{2}\right)\right)^{2}}+\cos \left(\frac{\alpha_{3} \pi}{Q_{3} \omega^{\alpha 3}}\right)(6) \\
Z^{\prime \prime}=\frac{R_{p 1}^{2} Q_{1} \omega^{\alpha 1} \sin \left(\frac{\alpha_{1} \pi}{2}\right)}{\left(1+R_{p 1} Q \omega^{\alpha 1} \cos \left(\alpha_{1} \frac{\pi}{2}\right)\right)^{2}+\left(R_{p 1} Q_{1} \omega^{\alpha 1} \sin \left(\alpha_{1} \frac{\pi}{2}\right)\right)}+\frac{R_{p 2}^{2} Q_{2} \omega^{\alpha 2} \sin \left(\frac{\alpha_{2} \pi}{2}\right)}{\left(1+R_{p 1} Q \omega^{\alpha 1} \cos \left(\alpha_{1} \frac{\pi}{2}\right)\right)^{2}+\left(R_{p 1} Q_{1} \omega^{\alpha 1} \sin \left(\alpha_{1} \frac{\pi}{2}\right)\right)}+\frac{\sin \left(\frac{\alpha_{3} \pi}{2}\right)}{Q_{3} \omega^{\alpha 3}}(7)
\end{gathered}
$$
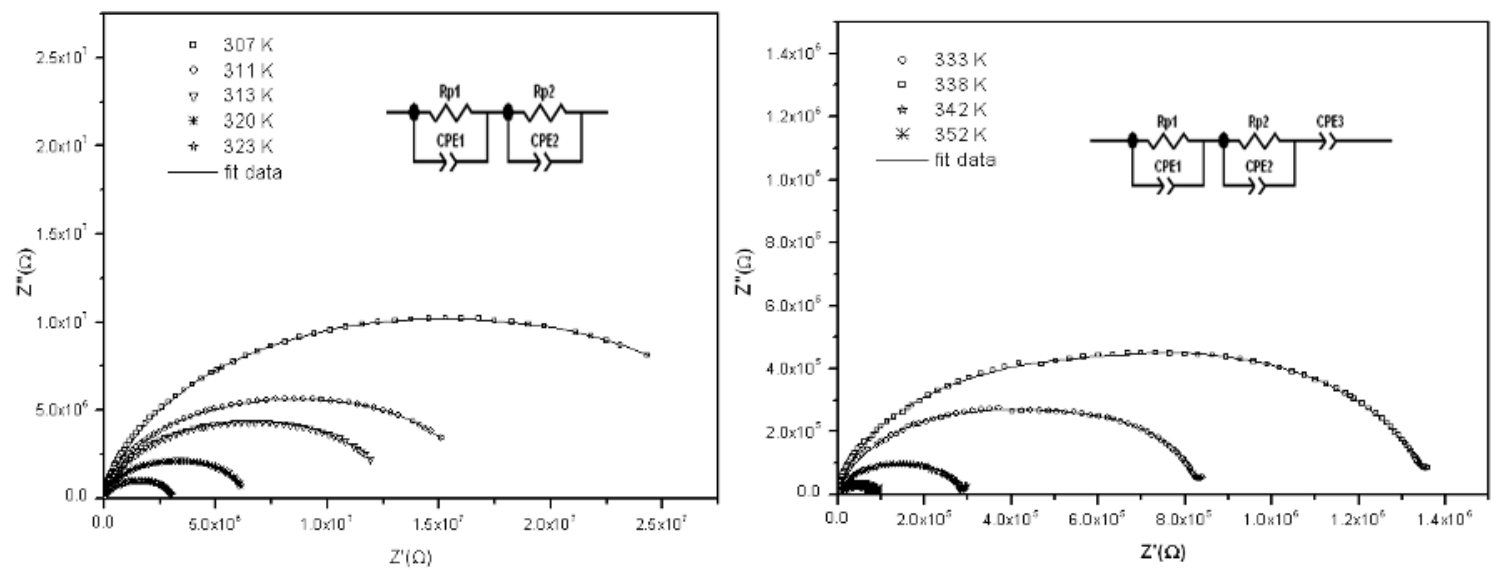

Fig.6. Experimental and simulation impedance data for $\left[\mathrm{C}_{2} \mathrm{H}_{10} \mathrm{~N}_{2}\right] \mathrm{Cd}(\mathrm{SCN})_{2}(\mathrm{Cl})_{2}$ at different temperatures. The insets show the proposed equivalent circuits.

Moreover figure 7 shows a good agreement between the experimental and simulation results of the real and the imaginary parts of impedance us function of frequency.

Additionally, the capacitance values calculated at the maximum frequency, $\omega_{\max }$, at $Z$ ' 'peaks using the relation $\omega_{\max } \mathrm{RC}=1$ are reported in Table 3 .

These low capacitances values ( $\mathrm{pF}$ order) are usually assigned to grain response rather than grain boundary, whose higher capacitance value is the $\mathrm{nF}-\mu \mathrm{F}$ order [10] 
Table 3. Temperature dependence of Rp, Q, and the fractional exponent $\alpha$.

\begin{tabular}{|lllllllll|}
\hline \multicolumn{7}{c|}{$\mathbf{T}<\mathbf{3 3 0 K}$} \\
\hline $\mathrm{T}(\mathrm{K})$ & $\mathrm{R}_{\mathrm{p} 1}\left(10^{6} \Omega\right)$ & $\alpha_{1}$ & $\mathrm{Q}_{1}(\mathrm{pF})$ & $\mathrm{R}_{\mathrm{p} 2}\left(10^{6} \Omega\right)$ & $\alpha_{2}$ & $\mathrm{Q}_{2}(\mathrm{pF})$ & \\
\hline 307 & 18.59 & 0.830 & 26.9 & 11.89 & 0.91 & 96.2 & & \\
311 & 10.70 & 0.836 & 90.7 & 6.49 & 0.88 & 21.8 & & \\
313 & 7.70 & 0.840 & 96.3 & 5.47 & 0.87 & 24.2 & & \\
315 & 5.67 & 0.850 & 103 & 4.43 & 0.86 & 26.0 & & \\
320 & 2.76 & 0.860 & 31 & 3.71 & 0.83 & 11.6 & & \\
\hline & & & \multicolumn{7}{c|}{$\mathbf{T}>\mathbf{3 3 0 K}$} & & & & \\
\hline $\mathrm{T}(\mathrm{K})$ & $\mathrm{R}_{\mathrm{p} 1}\left(10^{5} \Omega\right)$ & $\alpha_{1}$ & $\mathrm{Q}_{1}(\mathrm{pF})$ & $\mathrm{R}_{\mathrm{p} 2}\left(10^{5} \Omega\right)$ & $\alpha_{2}$ & $\mathrm{Q}_{2}(\mathrm{pF})$ & $\alpha_{3}$ & $\mathrm{Q}_{3}\left(10^{-7} \mathrm{~F}\right)$ \\
\hline 333 & 3.410 & 0.930 & 98 & 4.880 & 0.860 & 31.1 & 0.670 & 1.60 \\
336 & 2.370 & 0.890 & 135 & 3.120 & 0.870 & 31.9 & 0.750 & 1.14 \\
342 & 1.68 & 0.850 & 150 & 1.19 & 0.910 & 23.9 & 0.710 & 1.87 \\
352 & 0.38 & 0.810 & 53 & 0.45 & 0.930 & 19.2 & 0.810 & 1.16 \\
\hline
\end{tabular}
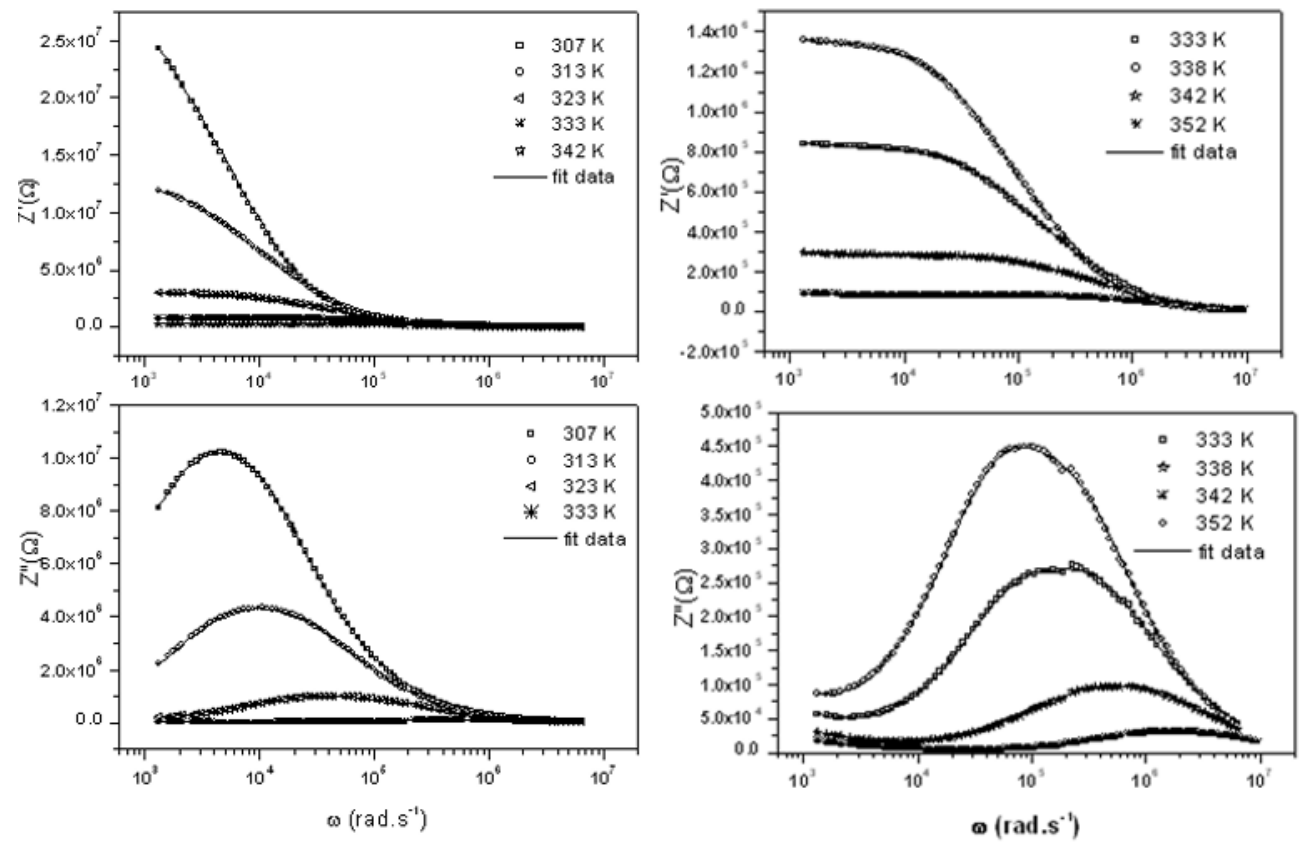

Fig.7. Frequency dependence of the $Z^{\prime}$ and $Z^{\prime \prime}$ of $\mathrm{C}_{2} \mathrm{H}_{10} \mathrm{~N}_{2} \mathrm{Cd}(\mathrm{SCN})_{2}(\mathrm{Cl})_{2}$ at various temperatures

\subsection{Conductivity}

The electrical conductivity at each temperature was obtained by using the formula $\sigma_{\mathrm{p}}=\mathrm{L} / \mathrm{Rp}$.A where $\mathrm{Rp}$ is the bulk resistance of the sample, at each temperature was obtained from the intercept of the semicircular portion on the real axis, $\mathrm{L}$ is the thickness and $\mathrm{A}$ is the area of cross section of the sample. Figure 8 shows the electrical conductivity vs-reciprocal temperature of polycrystalline $\mathrm{C}_{2} \mathrm{H}_{10} \mathrm{~N}_{2} \mathrm{Cd}(\mathrm{SCN})_{2}(\mathrm{Cl})_{2}$ between 300 and $370 \mathrm{~K}$ during heating run. The activation energy obtained from the slope of the straight line segment using the Arrhenius known relationship: 


$$
\sigma_{p} \cdot T=\sigma_{0} \exp \frac{-\Delta E_{a}}{k_{B} \cdot T}
$$

where $\sigma_{\mathrm{p}}$ is the electrical conductivity at temperature $\mathrm{T}, \sigma_{\mathrm{o}}$ the pre-exponential factor, $\mathrm{k}_{\mathrm{B}}$ the Boltzmann's constant and $\Delta \mathrm{E}_{\mathrm{a}}$ is the thermal activation energy for the ion migration yield to $\Delta \mathrm{E}_{\mathrm{a}}=(0.540(3)) \mathrm{eV}$ and $\sigma_{\mathrm{o}}=3.3510 \times 10^{6} \Omega^{-1} \mathrm{~cm}^{-1} \mathrm{~K}$.

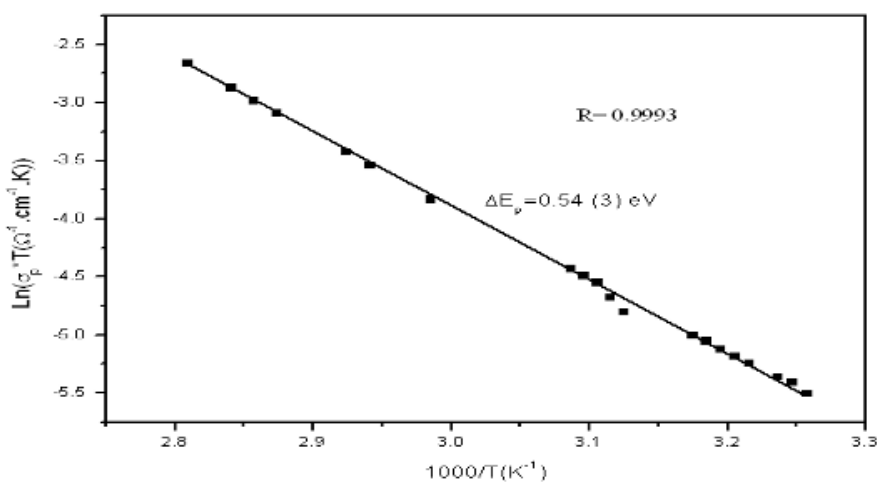

Fig.8. Variation of $\operatorname{Ln}\left(\sigma_{\mathrm{p}} \cdot \mathrm{T}\right)$ versus $(1000 / \mathrm{T})$ of $\mathrm{C}_{2} \mathrm{H}_{10} \mathrm{~N}_{2} \mathrm{Cd}(\mathrm{SCN})_{2}(\mathrm{Cl})_{2}$

\subsection{Dielectric studies}

The complex permittivity can be expressed as a complex number $\varepsilon^{*}(\omega)=\varepsilon^{\prime}(\omega)-\mathrm{i} \varepsilon^{\prime \prime}(\omega)$. The dielectric relaxation is described by a non-Debye model which gives the frequency dependent complex permittivity in the form [11]:

$$
\varepsilon^{*}(\omega)=\varepsilon^{\prime}+i \varepsilon^{\prime \prime}=\varepsilon_{\infty}+\frac{\varepsilon_{S}-\varepsilon_{\infty}}{1+\left(\frac{i \omega}{\omega_{1}}\right)^{1-\alpha}}+\frac{\sigma_{0}}{i \varepsilon_{0} \omega}
$$

where $\sigma_{\mathrm{o}}$ represents the specific conductivity of the title compound, $\varepsilon_{\mathrm{s}}$ is the static permittivity, $\varepsilon_{0}$ is the permittivity of the free space, $\varepsilon_{\infty}$ is the high frequency value of $\varepsilon$ " and $\omega_{1}$ is the relaxation angular frequency of the Debye process. The real part of $\varepsilon^{\prime}(\omega)$ and the imaginary part of $\varepsilon$ ' $(\omega)$ are expressed by:

$$
\begin{gathered}
\varepsilon^{\prime}(\omega)=\varepsilon_{\infty}+\frac{\left(\varepsilon_{s}-\varepsilon_{\infty}\right)\left[1+\left(\frac{\omega}{\omega_{1}}\right)^{1-\alpha} \cos \left(\frac{(1-\alpha) \pi}{2}\right)\right]}{1+2\left(\frac{\omega}{\omega_{1}}\right)^{1-\alpha} \cos \left(\frac{(1-\alpha) \pi}{2}\right)+\left(\frac{\omega}{\omega_{1}}\right)^{2(1-\alpha)}} \\
\varepsilon^{\prime \prime}(\omega)=\frac{\left(\varepsilon_{S}-\varepsilon_{\infty}\right)\left(\frac{\omega}{\omega_{1}}\right)^{1-\alpha} \sin (1-\alpha) \frac{\pi}{2}}{1+2\left(\frac{\omega}{\omega_{1}}\right)^{1-\alpha} \cos \left((1-\alpha) \frac{\pi}{2}\right)+\left(\frac{\omega}{\omega_{1}}\right)^{2(1-\alpha)}+\frac{\sigma_{0}}{\varepsilon_{0} \omega}}
\end{gathered}
$$

The first part in Eq.11 refers to the thermal polarization and the second one to the electrical conductivity [12]. Consequently, the loss factor is calculated as follows: 


$$
\tan (\varepsilon(\omega))=\varepsilon^{\prime \prime}(\omega) / \varepsilon^{\prime}(\omega)
$$

The frequency dependence of the dielectric function of a solid reflects the dynamic response of the constituents of the solid. Figure 9 shows that the dielectric constant decreases with increase in frequency. At low frequency due to space charge accumulation a gradual increase in the dielectric constant have been observed. At higher frequencies the change in the direction of the electric field lines is too fast to be followed by the charged ion and hence the dielectric constant decreases.
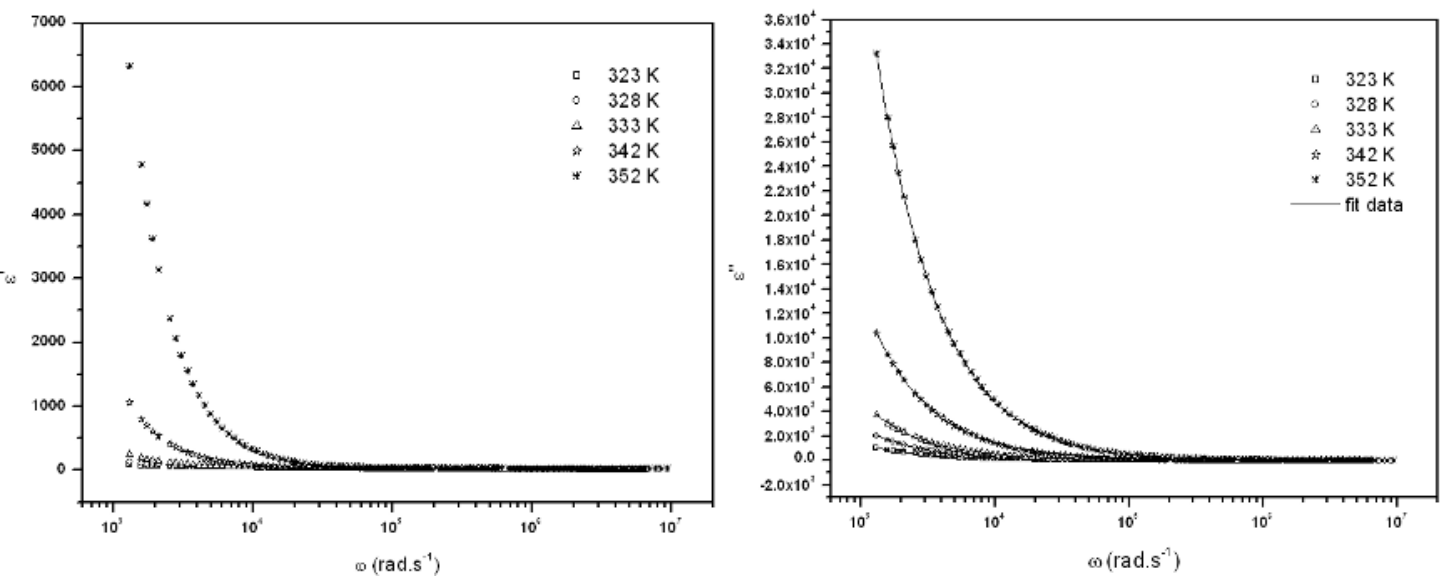

Fig.9. Frequency dependence of the real part $\left(\varepsilon^{\prime}\right)$ and the imaginary part permittivity $\left(\varepsilon^{\prime \prime}\right)$ with the best fitted data of complex permittivity of $\mathrm{C}_{2} \mathrm{H}_{10} \mathrm{~N}_{2} \mathrm{Cd}(\mathrm{SCN})_{2}(\mathrm{Cl})_{2}$ at various temperatures

Figure 9 shows also the frequency dependence of the imaginary part of the dielectric constant from fitting Eq. (11). There are no appreciable relaxation peaks in the frequency range employed in this study. The dielectric loss rises sharply at low frequency indicating that electrode polarization and space charge effects have occurred confirming non-Debye dependence [13]. The dielectric loss increases at higher temperatures due to the higher charge carrier density. The least squares fit parameters obtained for different temperatures are shown in Table 4.

Table 4. Least squares fit parameters of the imaginary part of permittivity ( $(")$

\begin{tabular}{|llll|}
\hline $\mathrm{T}(\mathrm{K})$ & $\omega_{1}\left(\mathrm{rad} . \mathrm{s}^{-1}\right)$ & $\alpha$ & $\sigma_{\mathrm{o}}\left(\Omega^{-1} \mathrm{~cm}^{-1}\right)$ \\
\hline 323 & 1053 & 0.68 & $1.23 .10^{-7}$ \\
328 & 1595 & 0.50 & $2.12 .10^{-7}$ \\
333 & 2550 & 0.67 & $3.51 .10^{-7}$ \\
342 & 7214 & 0.70 & $1.05 .10^{-6}$ \\
352 & 25180 & 0.50 & $3.6 .10^{-6}$ \\
\hline
\end{tabular}

Figure10 exhibits loss tangent $\tan (\varepsilon)$ variation with angular frequency and temperatures. The maximum in the $\tan (\varepsilon)$ peak shifts to higher frequency with rise of temperature. We noticed clearly that larger $\tan (\varepsilon)$ values are for higher temperatures. The $\tan (\varepsilon)$ increases with rise in frequency and showed a maximum at particular angular frequency $\omega p$ for different temperatures because the active component (ohmic) of the current increases more rapidly than its reactive component (capacitive). At higher frequencies $\tan (\varepsilon)$ decreases with increasing frequency because the active component of the current is practically independent of frequency and the reactive component increases in proportion to the frequency [14].

With respect to the different temperatures, the relaxation time, $\tau_{t}$, is calculated according to the resonance condition, which is defined by $\omega_{\mathrm{t}} \tau_{\mathrm{t}}=1$ from the peak maximum of $\tan (\varepsilon)$. The temperature dependence of $\tau_{\mathrm{t}}$ is plotted in figure 11. It is well described by the Arrhenius relation: 


$$
\tau_{t}=\tau_{0} \exp \left[-\frac{\Delta E_{t}}{k_{B} \cdot T}\right]
$$

where $\tau_{0}$ is the characteristic relaxation time and $\Delta \mathrm{E}_{\mathrm{t}}$ is the activation energy for the relaxation process, $\mathrm{k}_{\mathrm{B}}$ is the Boltzmann constant and $\mathrm{T}$ is the absolute temperature. The activation energy $\Delta \mathrm{E}_{\mathrm{t}}$ obtained from the loss tangent is about of $\left(\Delta \mathrm{E}_{\mathrm{t}}=0.530(3)\right) \mathrm{eV}$.

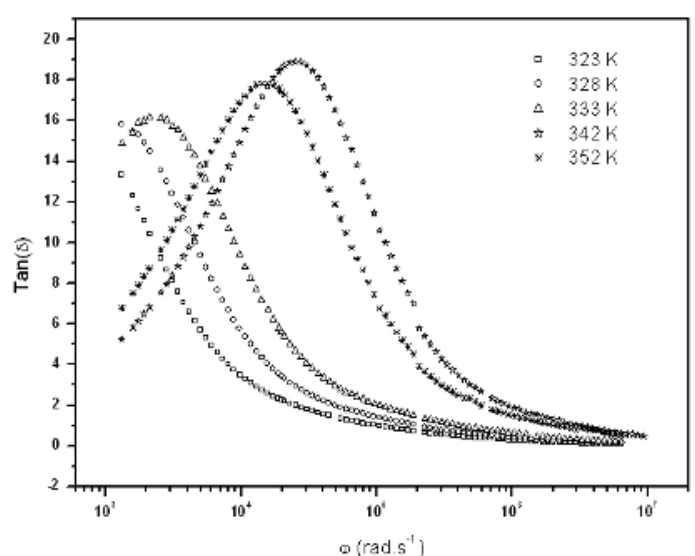

Fig.10. Frequency dependence of $\tan (\delta)$ at various temperatures

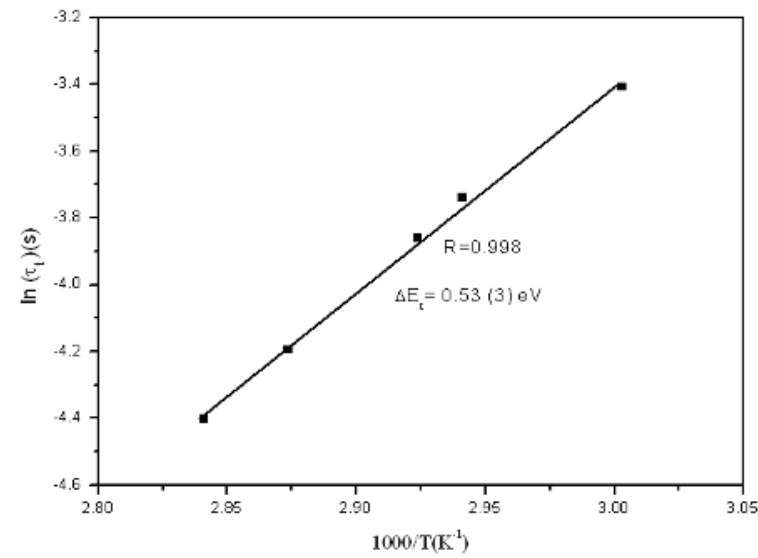

Fig.11. Variation of the relaxation time $\left(\tau_{t}\right)$ versus $(1000 / \mathrm{T})$

The activation energy for conduction $\left(\Delta \mathrm{E}_{\mathrm{a}}=(0.540(3) \mathrm{eV})\right.$ is almost the same as that of the activation energy for the relaxation process $\left(\Delta \mathrm{E}_{\mathrm{t}}=0.530(3)\right) \mathrm{eV}$. The near value of activation energies obtained from the analyses of conductivity data and circuit equivalent confirms that the conductivity deduced from the impedance arcs is dominated by the grain-interior conductivity, characterized by the hopping mechanism [15].

\section{Conclusions}

The crystalline complex was prepared and studied by mean single crystal X-ray diffraction, heteronuclear ${ }^{111} \mathrm{Cd},{ }^{13} \mathrm{C} \mathrm{CP} / \mathrm{MAS}$ NMR spectroscopy and impedance spectroscopy. The structure shows a layer arrangement: planes of $\left[\mathrm{CdCl}_{2}(S C N)_{2}\right]_{n}^{2-}$ chains alternate with planes of $\left[\left(\mathrm{NH}_{3}\right)_{2}\left(\mathrm{CH}_{2}\right)_{2}\right]^{2+}$. The cadmium atoms are bridged by two thiocyanate ions generating 1-D polymeric-chains. These chains are themselves interconnected by means of $\mathrm{N}-\mathrm{H} \ldots \mathrm{Cl}$ (NCS) hydrogen bonds originating from the organic cation $\left[\left(\mathrm{NH}_{3}\right)_{2}\left(\mathrm{CH}_{2}\right)_{2}\right]^{2+}$. The isotropic region of the ${ }^{111} \mathrm{Cd}$ CP/MAS NMR spectrum of $\left[\mathrm{C}_{2} \mathrm{H}_{10} \mathrm{~N}_{2}\right] \mathrm{CdCl}_{2}(\mathrm{SCN})_{2}$ shows spin-spin coupling of ${ }^{111} \mathrm{Cd}$ with two ${ }^{14} \mathrm{~N}$ indicates the presence of two equivalent thiocyanate ligands, in agreement with the results of

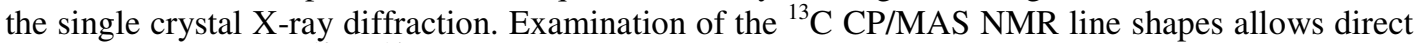
measurement of the ${ }^{13} \mathrm{C},{ }^{14} \mathrm{~N}$ dipolar coupling constant of $1381 \mathrm{~Hz}$. The analysis as function of temperatures of the frequency dispersion of the real and the imaginary components of the complex impedance allowed determining two equivalent circuits for this material. The near value of activation energies obtained from the analysis of the conductivity data and the equivalent circuit confirms that the transport is through ion hopping mechanism in the investigated material.

\section{Acknowledgments}

The authors would like to thank Dr. K. Eichele holder of the Department of Chemistry of Canada, for many helpful discussions and his assistance for the calculus of the simulated spectra. 


\section{References}

1. R. W. Asmussen and O. Bostrup, Acta Chem.Scand, 11 (1957)

2. G. M. Sheldrick, SHELXL PLUS.PC Version; a system of computer programs for the determination of crystal structures from X-ray diffraction data, Rev.5 (1998)

3. L. J. Farrugia, WinGX program for crystallography package. J. App. Cryst 32 (1999)

4. Mercury 2.3; a Crystal Structure Visualization and Exploration belonging to the Cambridge Crystallography Data Centre (CCDC)

5. International Tables for X-Ray Crystallography, Vol. II, Kynoch Press, Birmingham (1959)

6. K. Eichele, R. E. Wasylishen, J. Inorg. Chem. 33 (1994)

7. S. Andrew Lipton, S. Scott. Mason, Daniel L. Reger, and D. Paul Ellis, J. Am. Chem. Chem. Soc. 116 (1994)

8. A. C. Olivieri, L. Frydman, L. E. Diaz, J. Magn. Reson (1987)

9. G. M. Tsangaris, G. C. Psarras and N Kouloumbi, J. Mater. Sci.33 (1998)

10. Ye. Haittao, C. Sun, Hung d, P. Hing, Thin Solid Films 381 (2001)

11. B. Louati, K. Guidara, M. Gargouri Phys. Status. Solidi. B241 (2004)

12. N. Ponpandian, P. Balaya, and A. Narayanasamy, J. Phys. Condens. Mater 14 (2002)

13. X. Qian, N. Gu, Z. Cheng, X. Yang, S. Dong, Electrochim. Acta 46 (2001)

14. F. Erragh, A. Boukhari, B. Elouadi and F. Abraham, J. Solid State Chem. 120 (1995)

15. A. Ben Rhaiem. N. Zouari. K. Guidara. M. Gargouri. A. Daoud, J. Alloys Compd. 387 (2005) 